\section{Management of retinopathy in type 2 diabetes}

\section{The 'bad companions' of diabetes: should the ophthalmologist get involved?}

Diabetic retinopathy continues to be the most common cause of blindness in the working-age population. ${ }^{1}$ The incidence of diabetes continues to rise and despite our best efforts as clinicians, the complications of this disease continue to occur. It is estimated that by the year 2010 the world diabetic population will have doubled, reaching an estimated 221 million. $^{2}$ Although the increase in numbers will include type 1 diabetes, the rise will be predominantly due to type 2 . Interestingly, in this current issue of Eye Rhatigan et al. ${ }^{3}$ present the results of their study that shows the underlying cause of blindness in the majority of diabetics who are registered partially sighted or blind, is, in fact, not diabetic retinopathy. ${ }^{3}$

For those whose clinical practice encompasses the care of diabetics, some recent changes in terminology and recommendations are notable. Last year the American Diabetes Association revised the classification and diagnostic criteria for diabetes. ${ }^{4}$ The revised diagnostic criteria include the lowering of the fasting plasma glucose level required for diagnosis to a level of $7.0 \mathrm{mmol} / 1$ or greater; also the oral glucose tolerance test is no longer recommended for diagnostic purposes. The old terms IDDM and NIDDM have now been replaced by a classification based on aetiology. This categorises diabetes mellitus into four subgroups. Following on swiftly from this reclassification have come the long-awaited results of the United Kingdom Prospective Diabetes Study (UKPDS). ${ }^{5,6}$ The results of this study and those of the Hypertension Optimal Treatment (HOT) randomised trial published recently, have some important messages for clinician and patient alike. ${ }^{7}$

Approximately 30 years ago 'high blood glucose concentrations' and 'high blood pressure' were described as the two 'bad companions' of diabetes. The UKPDS has recently added two further bad companions: 'dyslipaemia and smoking'. ${ }^{8}$ In type 1 diabetes, the value of intense control of blood glucose in preventing the progression of long-term complications has been well demonstrated. ${ }^{9}$ However, for the more complex type 2 diabetes, up to now the importance of attending to these risk factors has been suspected but not strictly proven.

It has been known for many years that type 2 diabetes and hypertension are commonly associated conditions, with approximately $40 \%$ of patients with type 2 diabetes at the age of 45 years being hypertensive, the proportion rising to $60 \%$ at the age of 75 years. Studies have shown that hypertension increases the high risk of cardiovascular disease with type 2 diabetes and that it is also a risk factor for the development of nephropathy and microalbinuria. ${ }^{10}$ The UKPDS asked the following important questions: (1) Does the tight control of hypertension reduce the risk of complications in type 2 diabetes? (2) If it does, do ACE inhibitors offer any advantages over beta-blockers?

The UKPDS confirms that rigorous control of hypertension is indicated in type 2 diabetes. The first take-away message from the study is: Tight control of blood pressure, i.e. $<150 \mathrm{mmHg}$ systolic and $<85 \mathrm{mmHg}$ diastolic, reduces the risk of any non-fatal or fatal diabetic complication and also of death related to diabetes. Tight hypertensive control resulted in a $24 \%$ reduction in any diabetic complications and a $32 \%$ reduction in death. On the ophthalmic side there was a $34 \%$ reduction in the rate of progression of retinopathy by two or more steps on the ETDRS final scale and a $47 \%$ reduction in the deterioration of visual acuity by 3 lines on the ETDRS chart. ${ }^{5}$ This is the first report showing that in patients with type 2 diabetes, tight blood pressure control is important in reducing the risk of diabetic eye disease. The study also showed that: Beta-blockers and ACE inhibitors are equally efficacious in reducing the complications of diabetes. ${ }^{6}$ The level of the blood pressure control was the important factor rather than the agent used. Due to the high coexistence of diabetes and hypertension it is anticipated that the rigorous and early control of hypertension in
Giuliana Silvestri Department of Ophthalmology Royal Victoria Hospital Belfast, Northern Ireland BT12 6BA, UK 
diabetics 'will be financially demanding. In these times of financial awareness in health care, the cost-effectiveness of improved blood pressure control in type 2 diabetics as a measure of reducing the incidence and severity of complications was costed. The outcome of this economic exercise was that on both clinical and economic grounds the use of a policy of tightly controlled blood pressure in the hypertensive patient with type 2 diabetes was justified. $^{11}$

Diabetic retinopathy is common in patients with newly diagnosed type 2 diabetes. In a previous study retinopathy was found to be present in $39 \%$ of men and $35 \%$ of women at diagnosis. ${ }^{12}$ The severity of retinopathy was related in both sexes to fasting plasma glucose levels and higher systolic and diastolic pressures. As clinicians we know that, in general, laser photocoagulation is less efficacious in the treatment of diabetic maculopathy than in proliferative lesions. ${ }^{13}$ Any alternative strategy for the prevention of the progression of maculopathy would therefore be welcome.

In view of the above and of the strong evidence now confirming that hypertensive control is imperative in type 2 diabetics and is instrumental in reducing both macrovascular and microvascular complications, the question to be asked is whether ophthalmologists should be more actively involved in pursuing the four 'bad companions' of diabetes. Some patients who have retinopathy are also attending an endocrinologist; however, many are not. Should we as ophthalmologists be more holistic? Should the ophthalmologist routinely assess haemoglobin A1c levels, monitor blood pressure, check lipid profiles and also strongly dissuade the patient from smoking? Perhaps we should, or perhaps the time is now ripe for the planning of combined ophthalmological and endocrinological clinics for those with clinically detectable complications of diabetes mellitus.

\section{References}

1. Foulds WS, McCuish A, Barrie T, Green F, Scobie IN, Ghafour IM, et al. Diabetic retinopathy in the West of Scotland: its detection and prevalence, and the cost effectiveness of a proposed screening programme. Health Bull (Edinb) 1983;41:318-26.
2. Amos AF, McCarty DJ, Zimmet P. The rising global burden of diabetes and its complications: estimates and projections to the year 2010. Diabet Med 1997;14(Suppl 5):S1-85.

3. Rhatigan MC, Leese GP, Ellis J, Ellingford A, Morris AD, Newton RW, Roxburgh STD. Blindness in patients with diabetes who have been screened for eye disease. Eye 1999;13:166-9.

4. Expert Committee on the Diagnosis and Classification of Diabetes Mellitus. Report. Diabetes Care 1997;17:326-38.

5. UK Prospective Diabetes Study Group. Tight blood pressure control and risk of macrovascular and microvascular complications in type 2 diabetes. UKPDS 38. BMJ 1998;317:703-13.

6. UK Prospective Diabetes Study Group. Efficacy of atenolol and captopril in reducing risk of macrovascular and microvascular complications in type 2 diabetes: UKPDS 39. BMJ 1998;317:713-20.

7. Hansson L, Zanchetti A, Carruthers SG, Dahlof B, Elmfeldt D, Julius S, et al. for the HOT Study Group. Effects of intensive blood-pressure lowering and low-dose aspirin in patients with hypertension: principal results of the Hypertension Optimal Treatment (HOT) randomised trial. Lancet 1998;351:1755-62.

8. Turner RC, Millns H, Neil HAW, Stratton IM, Manley SE, Matthews DR, et al. for the United Kingdom Prospective Diabetes Study Group. Risk factors for coronary artery disease in non-insulin-dependent diabetes mellitus. UKPDS 23. BMJ 1998;316:823-8.

9. The DCCT Research Group. The effect of intensive treatment on the development and progression of long term complications in insulin-dependent diabetes mellitus. N Engl J Med 1993;329:977-86.

10. Hypertension in Diabetes Study Group. Prevalence of hypertension in newly presenting type 2 diabetic patients and the association with risk factors for cardiovascular and diabetic complications. HDS 1. J Hypertens 1993;11:309-17.

11. UK Prospective Diabetes Study Group. Cost effectiveness analysis of improved blood pressure control in hypertensive patients with type 2 diabetes. UKPDS 40. BMJ 1998;317:720-6.

12. Kohner EM, Aldington SJ, Stratton IM, Manley SE, Holman $R R$, Matthew DR, et al. Diabetic retinopathy at diagnosis of non-insulin-dependent diabetes mellitus and associated risk factors. UKPDS 30. Arch Ophthalmol 1998;116:297-303.

13. Early Treatment Diabetic Retinopathy Study Research Group. Photocoagulation for diabetic macular edema. ETDRS report 1. Arch Ophthalmol 1985;103:1796-806. 